\title{
A SITUAÇÃO DAS EMPREGADAS DOMÉSTICAS NA PRIMEIRA DÉCADA DO SÉCULO XXI, NO OESTE E NO SUDOESTE DA REGIÃO METROPOLITANA DE SÃO \\ PAULO
}

\begin{abstract}
Ailton Luchiari ${ }^{1}$
Resumo: Este artigo tem o objetivo de elaborar a caracterização das mulheres dedicadas aos serviços domésticos no mercado de trabalho. A análise de dados coletados e distribuídos pelos órgãos oficiais de recenseamento permitiu observar as transformações ocorridas no primeiro decênio deste século. As principais alterações foram observadas nos rendimentos, nos níveis de instrução, na formalização no emprego e na participação das mulheres no mercado de trabalho.
\end{abstract}

Palavras-Chave: emprego doméstico, mercado de trabalho, dados censitários.

Abstract: This article aims to prepare the characterization of women devoted to domestic labor market services. The analysis of data collected and distributed by the official organs of the census allowed to observe the changes in the first decade of this century. The main changes were observed in income, educational levels, in formal employment and the participation of women in the labor market.

Key-Words: domestic labor, labor market, census data

\section{INTRODUÇÃO}

A reestruturação produtiva da economia gera modificações na estrutura social das grandes cidades, muitos indivíduos estão migrando para o setor de serviços, o trabalho na indústria apresenta um decréscimo em suas vagas, o campo profissional está aberto às mulheres, e os jovens vislumbram, cada vez mais, sua inserção na sociedade por intermédio do trabalho. Entretanto, essas transformações no perfil do mercado de trabalho não incluem todos os indivíduos de maneira igualitária, pois os mais qualificados e instruídos, que são em menor número, alçam os melhores postos e os mais altos ganhos, enquanto os menos qualificados e com baixo nível de instrução, que podem ser muitos, passam ao largo das benesses advindas desse processo de mudanças econômicas e sociais. Nas grandes cidades os que conseguem os altos postos irão habitar nos melhores lugares, aqueles mais caros e repletos

\footnotetext{
${ }^{1}$ Possui graduação em Bacharelado Em Geografia pela Universidade Estadual Paulista Júlio de Mesquita Filho (1980), mestrado em Sensoriamento Remoto pelo Instituto Nacional de Pesquisas Espaciais (1985) e doutorado em Geografia (Geografia Física) pela Universidade de São Paulo (1993). Livre Docência em 2013 pela Universidade de São Paulo. Atualmente é professor assistente doutor da Universidade de São Paulo. Tem experiência na área de Geociências, com ênfase em Geoprocessamento, atuando principalmente nos seguintes temas: geoprocessamento, cartografia ambiental, sensoriamento remoto, tratamento digital de imagens e sistema de informação geográfica.
} 
de serviços essenciais e de instalações destinadas ao lazer; enquanto os destituídos de elevadas posições no mercado de trabalho irão morar em lugares menos valorizados, onde há falta de serviços e de equipamentos de lazer.

São nessas grandes cidades, as metrópoles dos países em desenvolvimento tardio e em seus espaços luminosos, que aparecem as novas ocupações no mercado de trabalho ligadas aos serviços de gestão, assessoria, administração, consultoria, publicidade, eventos, comércio exterior, tecnologia da informação, setor financeiro, dentre outras (BERNARDES, 2011). São ocupações, em sua maior parcela, ligadas ao setor quaternário, as quais exigem níveis altíssimos de qualificação e instrução, são aquelas atribuições para as pessoas aptas a manipular objetos técnicos (SANTOS; SILVEIRA, 2011). Pode ser, também, que exista uma parcela preponderante do trabalho feminino participando deste novo mercado de trabalho, como apontado por Castells (1999: 318). São essas profissões, em sua maioria, que comandam um país e, por sua vez, efetuam conexões com o mundo.

Essa parcela de profissionais pode representar uma fração minúscula dentro da força de trabalho dessas grandes metrópoles. Borges (2005) revela que na Região Metropolitana de Salvador foram criados 48.000 novos empregos formais no período entre janeiro de 2003 e julho de 2005. Desses empregos criados, grande parte $(91 \%)$ foi absorvida pelos trabalhadores com, pelo menos, nível equivalente ao grau médio de escolaridade. Desta cifra $14 \%$ correspondem aos profissionais com diploma universitário.

Em estudo sobre o mercado de trabalho na Região Metropolitana de Porto Alegre, no período de 1980 a 1990, Mammarella et al (2001) comentam que houve aumento da participação de trabalhadores com nível de escolaridade equivalente ao médio. Outro fato relevante é que os empregos aumentaram para os trabalhadores sem escolaridade, ou com baixo nível de instrução, e para os trabalhadores com nível de escolaridade superior, evidenciando os extremos. Quanto à localização, comentam que a elite dirigente e intelectual se concentra na capital, assim como os trabalhadores da administração pública, do legislativo e dos serviços especializados, enquanto que os outros trabalhadores habitam as outras cidades da região metropolitana.

Em Brasília, que é um caso metropolitano com características singulares, a presença do Estado tem implicações marcantes na desigualdade socioespacial. O Plano Piloto concentra os empregados do setor público, os que têm mais chances de receber maiores salários e habitar as áreas providas de infraestrutura urbana, enquanto as cidades satélites, precárias 
em serviços urbanos essenciais, abrigam uma população pobre com alta mobilidade pendular. (GUIA et al, 2010).

Esses estudos demonstram, de maneira resumida, que nas metrópoles do Brasil existem diferenciações entre a população. As melhores chances são destinadas aos detentores do maior nível de escolaridade e qualificação. Dentre estes estão os letrados, os que alçam as profissões novas e os indivíduos da elite tradicional.

A grande cidade apresenta os espaços luminosos, mas, ao mesmo tempo, constitui o espaço dos pobres, dos excluídos, das minorias, onde esses podem sobreviver (SANTOS, 2006). É o lugar de atração da grande massa de migrantes que não pode mais subsistir no campo. Exercem atividades econômicas tradicionais e marginalizadas e habitam os lugares opacos, áreas sem modernidade, dentro da grande cidade. Esses atores não participam do círculo da racionalidade hegemônica, mas a esta racionalidade, de certo modo, estão subordinados.

Esses espaços opacos revelam que nem todos participam da riqueza das grandes cidades, são espaços onde aparecem as oficinas mecânicas de automóveis, de reparos de máquinas e eletrodomésticos, e onde habitam as faxineiras, as domésticas, os trabalhadores da construção civil que efetuam pequenas reformas. Como salienta Silveira (2004), para esta camada da população, as próprias moradias tornam-se os espaços de seus pequenos negócios, como os das costureiras e o dos proprietários de veículos que fazem pequenos carretos e pequenas mudanças. Serviços e ocupações, em sua maioria, dificilmente revelados pelas estatísticas coletadas pelos órgãos oficiais.

$\mathrm{Na}$ grande cidade encontra-se uma densidade técnica bastante alta, há uma gama enorme de objetos carregados de informação, há os espaços luminosos. Nessas cidades são encontradas as formas mais significativas de segregação e de desigualdade, pois também é o lugar da pobreza urbana e do espaço dividido (SANTOS, 2009; 2004).

No âmbito do circuito inferior da economia urbana o trabalho doméstico ocupa posição significativa. Santos (2004: 208-209 e 2008: 65) afirma que o trabalho doméstico é uma das formas mais primitivas de ocupação e está enquadrado na categoria de serviços. Na Ásia esses serviços são desenvolvidos por homens e na América Latina, essencialmente, exercidos por mulheres. Constitui-se também em uma das primeiras atividades oferecidas aos recémchegados à grande cidade, pois não exige qualificação e se caracteriza por um trabalho desprovido de conteúdo. No Brasil, nas últimas décadas, este serviço, ou trabalho 
doméstico, atividade predominantemente feminina, tem sido objeto de vários princípios normativos a fim de torná-lo legalizado.

Devido à importância do serviço doméstico, principalmente no circuito inferior da economia urbana, esta pesquisa busca oferecer um panorama das transformações relacionadas a este tipo de trabalho, desenvolvido exclusivamente pelas mulheres, nas Sub-Regiões Oeste e Sudoeste da Região Metropolitana de São Paulo (RMSP). Tomou-se como referência o período delimitado pelos dois últimos recenseamentos gerais. A fonte de dados foram os questionários da amostra aplicados nos censos de 2000 e de 2010. Esses dados levam em conta os limites das menores unidades administrativas brasileiras, os municípios, pois não há garantia de que façam referência espacial à mesma Área de Ponderação, ou às Áreas de Expansão Domiciliar (AED), visto que essas mudam, a cada censo realizado. Em vista da metodologia empregada pelo IBGE, os limites de cada município da área de estudo foram considerados como unidades espaciais de análise para verificação das transformações ocorridas entre as datas. A tabulação dos questionários possibilitou a seleção das pessoas do sexo feminino que declararam exercer atividades relacionadas aos serviços domésticos.

O tratamento dos dados permitiu efetuar estimativas sobre a quantidade de domésticas, bem como realizar algumas observações sobre seus atributos qualificadores nas datas pesquisadas. As estimativas e proporções são apresentadas sob a forma tabela contendo valores relativos. Os principais atributos analisados para as duas datas do censo foram a participação das domésticas em relação à população economicamente ativa feminina, as alterações sofridas no nível de renda pelas domésticas, a variação da formalidade e informalidade neste tipo de emprego, as mudanças quanto ao grau de instrução dessas mulheres, a participação de mulheres brancas, negras e pardas em serviços domésticos, e, por fim, os diferenciais na origem dos fluxos migratórios das domésticas. Não houve, porém, a possibilidade de avaliar as diferenças nos fluxos pendulares, pois os dados do último recenseamento, o de 2010, não descreve esse tópico, ou seja, as questões relativas ao município onde se encontra a moradia e onde se encontra o local de trabalho foram substituídas pelo tempo de deslocamento para se chegar ao local de trabalho. 


\section{O Oeste e o Sudoeste da Região Metropolitana de São Paulo}

A área de estudo desta pesquisa foram o Oeste e o Sudoeste da RMSP, espaço que engloba os municípios de Barueri, Carapicuíba, Cotia, Embu das Artes, Itapecerica da Serra, Itapevi, Jandira, Osasco, Taboão da Serra e Vargem Grande Paulista. Situa-se, aproximadamente, entre os meridianos $46{ }^{\circ} 5^{\prime}$ e $47^{\circ} 05^{\prime}$ de longitude Oeste e entre os paralelos $23 \circ 25^{\prime}$ e $23 \circ 45^{\prime}$ de latitude Sul (figura 1)

A área apresenta usos diversos, desde locais densamente urbanizados, ocupados por pessoas ricas e pobres, locais destinados às atividades agrícolas, enclaves fortificados horizontais, áreas industriais e as destinadas às operações logísticas, os centros de serviços do terciário moderno, além dos centros das cidades que funcionam como os locais de serviços ligados ao comércio e à administração. Uma região com características de zona pericentral (AMORIN FILHO, 2005), ou da fronteira urbana (TORRES, 2005), por apresentar a diversificação de uso da terra e por ser receptora de um intenso fluxo migratório, nos últimos trinta anos, o que lhe confere um crescimento populacional significativo.

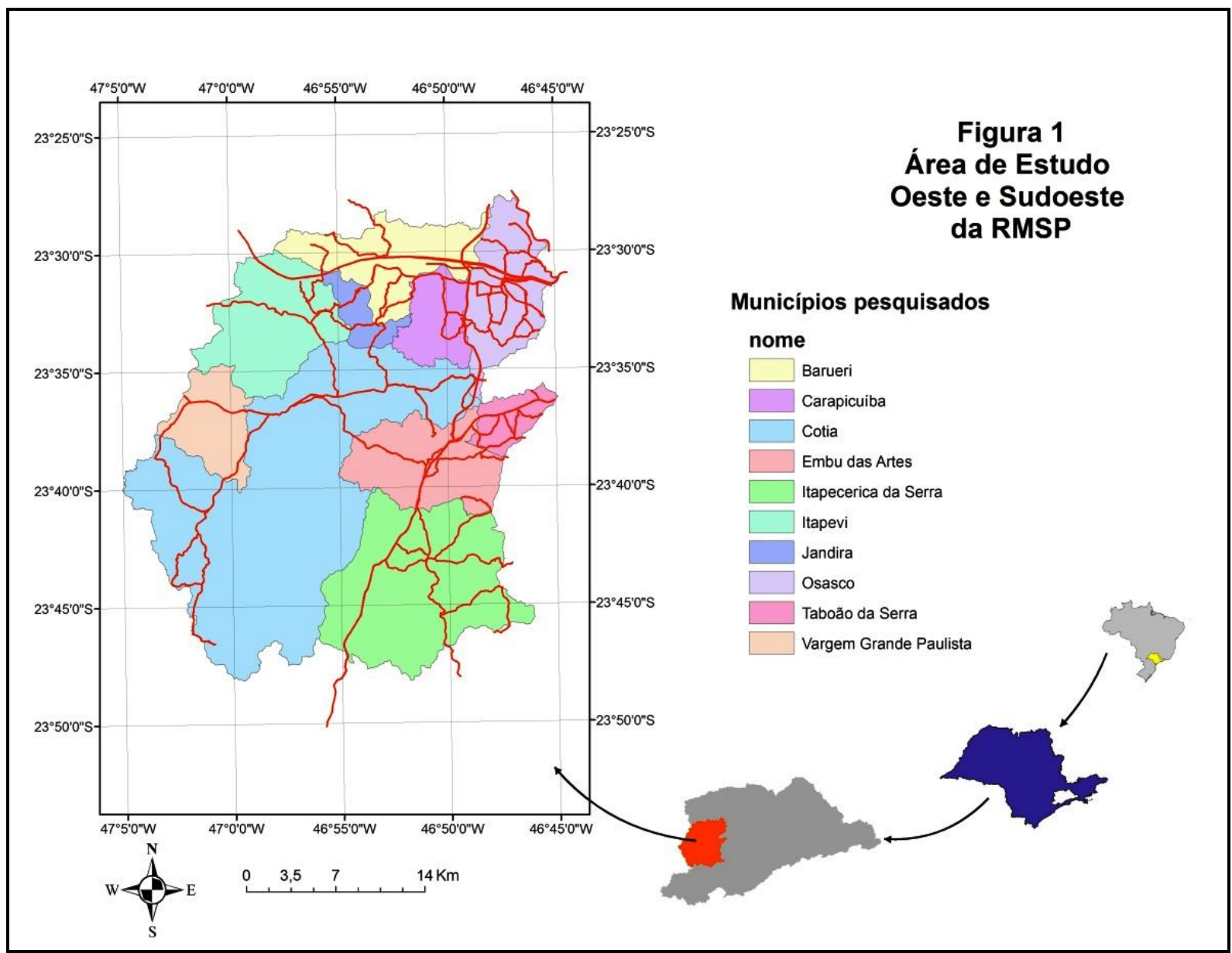


Três importantes rodovias; a Castello Branco, a Raposo Tavares e a Régis Bitencourt; e a via férrea da Companhia Paulista de Trens Metropolitanos (CPTM) comandam a expansão urbana. As estradas vicinais, em trajetos perpendiculares aos grandes eixos de circulação, transformaram-se em ruas e avenidas, contribuindo para a consolidação do tecido urbano. Estradas deste tipo ainda conservam grandes glebas de terras em suas cercanias, tornandoas, em curto espaço de tempo, objeto de especuladores imobiliários, tanto para a instalação dos loteamentos populares, quanto para a implantação dos empreendimentos destinados à população de renda mais alta.

Pode, também, ser constatado que as regiões Oeste e Sudoeste da RMSP apresentam diversidade de usos. Moradias edificadas, pelo processo de autoconstrução, estão disseminadas por toda a área. Condomínios fechados, concentrados e em alguns locais específicos são perceptíveis na paisagem, mas há também os que se encontram dispersos em outros territórios municipais. Conjuntos habitacionais implantados pelos governos municipais e pelo estadual onde predominam os habitantes com renda mais baixa. Centros de sedes municipais dominados pelo comércio e pelos serviços administrativos, habitados por uma parcela da população que percebe rendimentos médios. Residências campestres ocupadas aos finais de semana pelos seus proprietários, os quais têm como objetivo temporário o descanso da vida atribulada e acelerada da cidade. Concentrações de edifícios industriais, principalmente em localidades adjacentes às rodovias. Comércio, serviços e equipamentos destinados ao lazer, dispersos linearmente junto aos eixos de circulação, ou concentrados em algumas localidades específicas. Atividades agrárias exercidas em pequenos sítios situados às margens das estradas rurais, assim como as outras atividades primárias minerárias.

\section{Os Dados e o seu tratamento}

De acordo com o FIBGE (2003), durante o recenseamento geral, realizado de dez em dez anos, são aplicados dois tipos de questionários à população, no período de quatro meses do levantamento. O questionário básico é aplicado a todas as unidades domiciliares e são levantadas as informações básicas sobre os domicílios e sobre os seus moradores. 0 questionário da amostra, como o próprio nome faz referência, introduzido no censo de 1960, consiste em um questionário ampliado. Este contém um grande número de perguntas, 
é aplicado em $10 \%$ da população, em municípios com mais de 20 mil habitantes, e em $20 \%$ da população, em municípios com população igual ou menor que 20 mil habitantes. Este questionário composto de mais de uma centena de questões, além de conter aquelas do questionário simplificado, aborda temas relacionados a cada pessoa moradora do domicílio (sexo, idade, fecundidade, migração, mortalidade), às suas características socioeconômicas (ocupação, renda, nível de instrução, deficiências relativas à saúde) e aos aspectos referentes aos domicílios (número de dormitórios, material construtivo, abastecimento de água, conexão à rede geral de esgoto, bens de consumo existentes em cada domicílio).

A disseminação dos dados é efetuada por meio de dois procedimentos básicos: as informações gerais são divulgadas em agregados por setor censitário e as informações da amostragem por áreas de ponderação (AP), também denominadas de áreas de expansão domiciliar (AED). O setor censitário em áreas urbanas corresponde a uma unidade espacial, ou superfície, que comporta 300 domicílios, em média. Os dados agregados por setor são informações que já sofreram um tratamento prévio, e são divulgadas em blocos designados a abranger quatro aspectos fundamentais, a saber: as variáveis sobre o domicílio, sobre os responsáveis, sobre os habitantes e as informações sobre a instrução dos moradores. 0 número total de domicílios, a quantidade de domicílios ligados à rede geral de água, os domicílios com lixo coletado, dentre outras informações, são atributos referentes aos domicílios. O quantitativo de moradores por setor, o número total de homens, o número total de mulheres são algumas das variáveis que tratam dos habitantes residentes nos setores. As informações sobre os responsáveis são variáveis que se reportam aos chefes de domicílio, como a sua renda, a sua idade e o seu grau de instrução. O bloco sobre as pessoas trazem informações sobre a estrutura etária dos habitantes residentes em cada setor, e o bloco de instrução refere-se às informações sobre o analfabetismo e sobre o nível de instrução dos habitantes.

As áreas de ponderação correspondem a um conjunto de setores censitários e envolvem 400 domicílios amostrados (FIBGE, 2002). Considerando que a cada setor censitário urbano são amostrados 30 domicílios em média, cada área de ponderação corresponde a um grupo de 12 a 14 setores, aproximadamente. Os dados de cada uma dessas áreas de ponderação são divulgados sob a forma de questionários respondidos, um para cada um dos domicílios, e um para cada habitante, ou pessoa moradora em cada domicílio. Para cada área de ponderação são 1.350 questionários, aproximadamente, referentes aos moradores, contendo variáveis 
importantes, ou seja, cada pessoa deve responder a mais de uma centena de questões em cada questionário. Apesar da área de ponderação ocupar uma área maior, pois agrupa setores censitários, a grande vantagem é que os dados são brutos, ou podem ser considerados brutos embora coletados por órgãos oficiais. Os dados fornecidos perfazem um conjunto de questionários para cada área de ponderação. Para extrair informações importantes dos dados é necessário submetê-los ao processo de tabulação, e esta operação envolve rotinas computacionais baseadas em álgebra booleana encontradas em programas de banco de dados e de planilhas eletrônicas.

Os questionários da amostra, ou microdados da amostra, são produzidos e distribuídos pelo IBGE em formato de texto, isto é, linhas contendo caracteres alfanuméricos. Os dados em forma de texto necessitam conversão de formato para as planilhas eletrônicas a fim de serem tabulados. A conversão de formato texto para o formato planilha eletrônica foi realizada mediante o uso do programa computacional Statistical Package for Social Sciences (SPSS $\left.{ }^{\circledR}\right)$, licenciado pela Universidade de São Paulo. Neste mesmo programa estatístico foram selecionadas, dos questionários, as variáveis caracterizadoras das mulheres que desempenham serviços domésticos, correspondentes a cada Área de Ponderação e, depois, efetuou-se a transferência dos dados ao programa de planilha eletrônica (Excel ${ }^{\circledR}$ ) para posterior tabulação.

A análise temporal, utilizando-se dos microdados de 2000 e 2010, teve como objetivo avaliar as mudanças ocorridas em relação aos serviços domésticos desempenhados pelas mulheres, ou seja, o objetivo foi analisar as condições das empregadas domésticas na primeira década do século XXI. As variáreis qualificadoras foram similares para as duas épocas, tanto para o recenseamento realizado em 2000 quanto para o realizado em 2010. Ressalta-se que as unidades espaciais examinadas foram os municípios, pois as Áreas de Ponderação não são as mesmas para as duas datas, assim, os dados só puderam ser associados aos municípios.

As tabelas elaboradas nas etapas anteriores foram inseridas no Sistema de Informação Geográfica com o propósito de geração de mapas temáticos. O mapa produzido retrata valores relativos à População Economicamente Ativa Feminina e os valores absolutos desta categoria socioprofissional. 


\section{RESULTADOS}

As estimativas baseadas na população absoluta feminina para cada município e a proporção de domésticas, obtidas mediante a tabulação dos questionários, estão contidas na tabela 1 e figura 2. O resultado dessa aproximação comprova o aumento no número absoluto de mulheres empregadas em serviços domésticos, decorrente do aumento populacional absoluto em nível municipal no intervalo dos dez anos. Apesar de existir acréscimo no número absoluto de empregadas domésticas, sendo o maior representante o município de Embu das Artes, os aumentos relativos foram bem mais pronunciados para Itapevi, com 68,86\%, Itapecerica da Serra, com 65,46\%, e Cotia, com 56,86\%. Fato interessante é que o leste do município de Embu das Artes quanto o de Itapecerica da Serra possuem limites com o município sede da RMSP, nesses locais ocorrem a proliferação de loteamentos populares, irregulares e clandestinos, que detém um contingente significativo da população mais pobre e de migrantes. Pode ser verificado também que o norte de Cotia e o município de Itapevi compreendem localidades concentradoras de pessoas relacionadas às atividades de prestação de serviços domésticos, áreas classificadas como dormitório, conforme a pesquisa realizada por Meyer, Grostein e Biderman (2004).

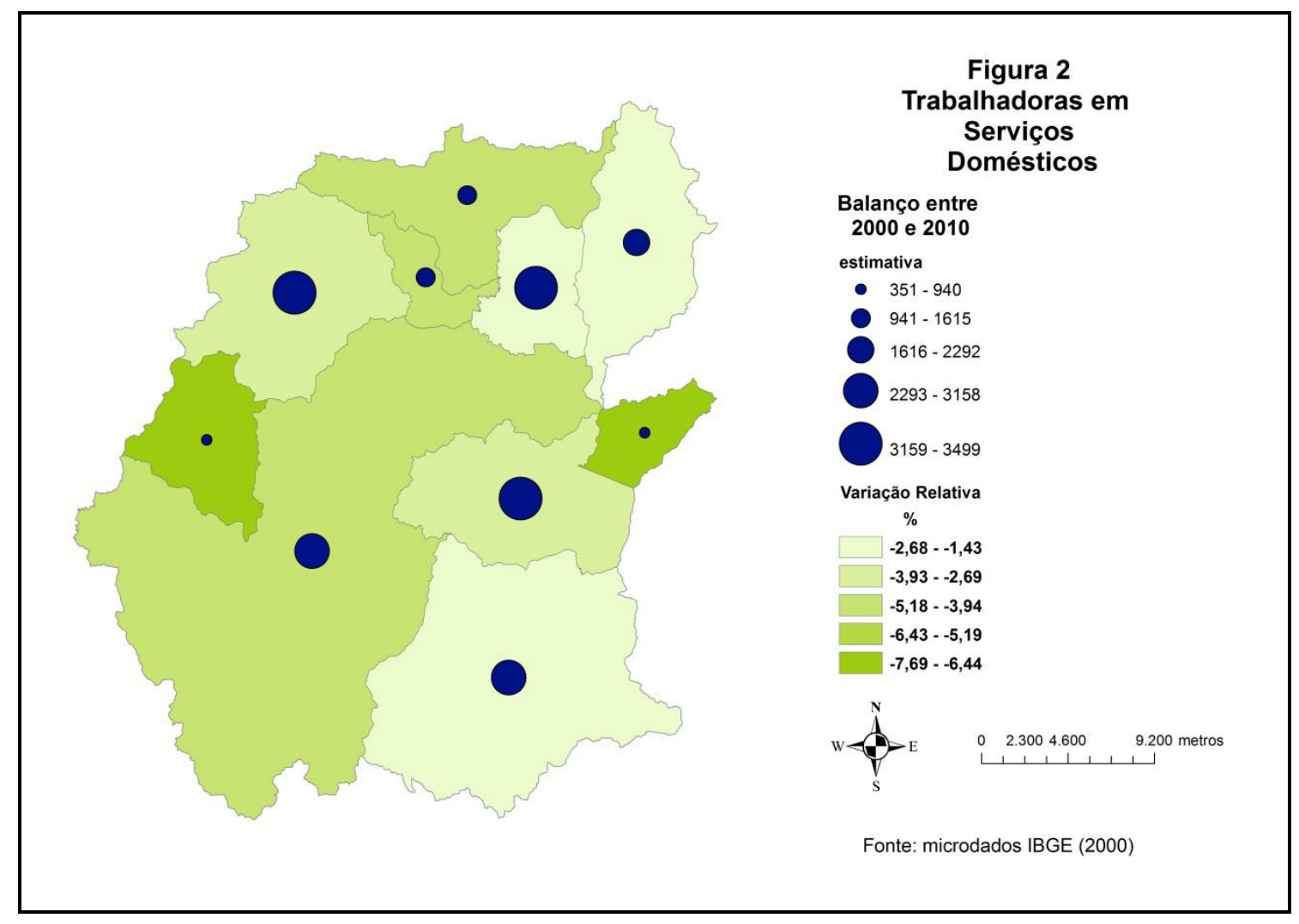




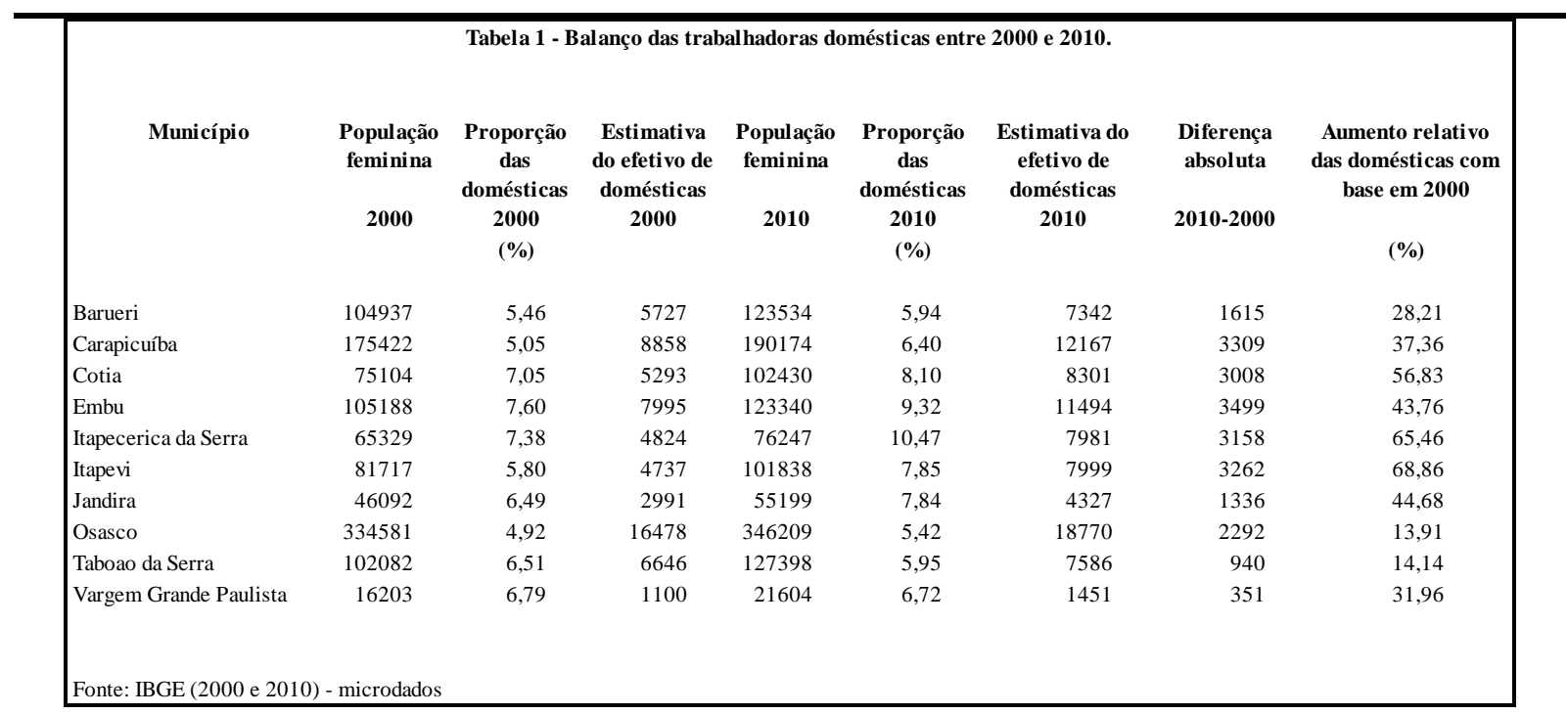

As informações relativas à PEA feminina, ao aumento negativo na proporção das empregadas domésticas, à elevação da idade das trabalhadoras nesse ramo de serviços, bem como sobre o diferencial de renda, são demonstrados na tabela 2. Os resultados revelam maior participação feminina no conjunto da PEA, formada por homens e mulheres, dentro da área estudada. 0 aumento relativo atingiu a proporção média de 6\%, aproximadamente, passando de 38\%, em 2000, para 44\%, em 2010. As diferenças significativas foram verificadas em quatro municípios: Itapecerica da Serra (7,09\%), Itapevi (7,02\%), Jandira $(6,78 \%)$ e Cotia $(6,53 \%)$. O aumento das mulheres no mercado de trabalho é apresentado como uma tendência geral na economia mundial, como aponta Castells (1999), fato que, também, ocorre na parte oeste e sudoeste da RMSP. Conforme Costa e Ribeiro (2010), a inserção da mulher no mercado de trabalho acelerou, após 1980, fatores como a queda da fecundidade e a elevação do nível de instrução foram decisivos para o aumento da participação feminina no mercado de trabalho. Essa participação feminina também sofreu acréscimo no ramo das ocupações relacionadas às atividades industriais, pois Leite (2003) verificou, por exemplo, o aumento do trabalho feminino na cadeia produtiva de automóveis. Apesar desse aumento, Leite (2003) ainda sustenta que as tarefas desempenhadas pelas mulheres não exigem qualificação profissional, as quais são caracterizadas pelo trabalho destituído de conteúdo, e que seus ganhos mensais chegam a aproximadamente dois terços daqueles percebidos pelos homens. 


\begin{tabular}{|c|c|c|c|c|c|c|}
\hline \multirow[t]{2}{*}{ Município } & $\begin{array}{c}\text { Proporção } \\
\text { da PEA } \\
\text { feminina }\end{array}$ & $\begin{array}{c}\text { Proporção } \\
\text { da PEA } \\
\text { feminina }\end{array}$ & \multirow{2}{*}{$\begin{array}{c}\text { Difer ença } \\
\text { Proporcional } \\
2010-2000 \\
2010-2000 \\
(\%)\end{array}$} & \multirow{2}{*}{ 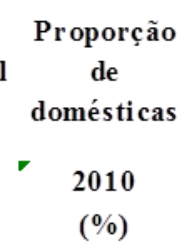 } & \multirow{2}{*}{$\begin{array}{c}\begin{array}{c}\text { Proporção } \\
\text { de }\end{array} \\
\text { domésticas } \\
2000 \\
(\%)\end{array}$} & \multirow{2}{*}{$\begin{array}{c}\text { Diferença } \\
\text { Proporcional } \\
\text { das domésticas } \\
2010-2000 \\
(\%)\end{array}$} \\
\hline & $\begin{array}{c}2010 \\
(\%)\end{array}$ & $\begin{array}{c}2000 \\
(\%)\end{array}$ & & & & \\
\hline Barueri & 43,10 & 37,65 & 5,46 & 14,97 & 19,89 & $-4,92$ \\
\hline Carapicuiba & 43,92 & 38,40 & 5,52 & 16,78 & 18,21 & $-1,43$ \\
\hline Cotia & 45,57 & 39,04 & 6,53 & 18,32 & 22,95 & $-4,63$ \\
\hline Embu & 44,38 & 39,10 & 5,28 & 24,00 & 27,54 & $-3,54$ \\
\hline Itapecerica da Serra & 44,81 & 37,71 & 7,09 & 25,45 & 27,02 & $-1,58$ \\
\hline Itapevi & 43,38 & 36,36 & 7,02 & 20,85 & 24,28 & $-3,44$ \\
\hline Jandira & 43,52 & 36,74 & 6,78 & 18,59 & 23,46 & $-4,87$ \\
\hline Osasco & 45,06 & 40,65 & 4,41 & 13,09 & 15,43 & $-2,34$ \\
\hline Taboao da Serra & 47,12 & 41,68 & 5,44 & 12,39 & 20,01 & $-7,62$ \\
\hline Vargem Grande Paul ista & 42,48 & 36,52 & 5,96 & 16,76 & 24,46 & $-7,69$ \\
\hline Município & $\begin{array}{c}\text { Idade } \\
\text { média das } \\
\text { domésticas }\end{array}$ & $\begin{array}{c}\text { Idade } \\
\text { média das } \\
\text { domésticas } \\
2000\end{array}$ & $\begin{array}{c}\text { Difer ença em } \\
\text { idade médi a } \\
\text { das } \\
\text { domésticas } \\
\text { entre } \\
2010-2010\end{array}$ & $\begin{array}{l}\begin{array}{c}\text { Renda } \\
\text { média das } \\
\text { domésticas }\end{array} \\
2010 \\
\text { (s.m.) }\end{array}$ & $\begin{array}{c}\text { Renda } \\
\text { média das } \\
\text { domésticas }\end{array}$ & $\begin{array}{c}\text { Diferença da } \\
\text { renda das } \\
\text { domésticas }\end{array}$ \\
\hline Barueri & 40,47 & 35,06 & 5,41 & 1,22 & 2,08 & $-0,87$ \\
\hline Carapicuiba & 41,08 & 35,82 & 5,26 & 1,21 & 2,17 & $-0,96$ \\
\hline Cotia & 41,26 & 36,49 & 4,77 & 1,25 & 2,03 & $-0,78$ \\
\hline Embu & 41,12 & 36,69 & 4,43 & 1,26 & 2,39 & $-1,13$ \\
\hline Itapecerica da Serra & 41,14 & 36,29 & 4,85 & 1,17 & 2,08 & $-0,92$ \\
\hline Itapevi & 40,11 & 36,51 & 3,60 & 1,18 & 2,07 & $-0,89$ \\
\hline Jandira & 41,95 & 36,19 & 5,76 & 1,15 & 2,08 & $-0,93$ \\
\hline Osasco & 42,59 & 36,31 & 6,28 & 1,14 & 2,03 & $-0,89$ \\
\hline Taboao da Serra & 42,52 & 36,81 & 5,70 & 1,46 & 2,24 & $-0,78$ \\
\hline Vargem Grande Paul ista & 39,55 & 34,40 & 5,15 & 1,05 & 1,78 & $-0,74$ \\
\hline
\end{tabular}

Apesar da ampliação da parcela das mulheres no mercado de trabalho, o conjunto das empregadas não seguiu o mesmo percurso, houve queda proporcional desta categoria socioprofissional. $\mathrm{Na}$ área estudada observa-se uma ligeira queda ao redor de $4 \%$, indicativo de que as mulheres estão migrando para outras categorias socioprofissionais no mercado de trabalho. Dentre as unidades administrativas estudadas, as quedas mais evidentes foram verificadas em Vargem Grande Paulista (-7,69\%) e Taboão da Serra (-7,62\%). Apesar das 
quedas ocorridas nesses municípios, o subconjunto das empregadas domésticas ainda possui participação expressiva na PEA feminina, revelada pelas altas taxas referentes à 2010, atingindo a média proporcional de $18,12 \%$.

Ao contrário das quedas verificadas nos atributos analisados até o momento, constata-se um aumento na idade média dessas trabalhadoras domésticas. Isto comprova a inexistência de inserção de um contingente de mulheres mais jovens para desempenhar as atividades em serviços domésticos. Dentro do mercado de trabalho, as mulheres jovens possivelmente mais qualificadas e instruídas, tiveram outras oportunidades. No período estudado, entre 2000 e 2010, a idade média de uma empregada doméstica passou de 36 para 41 anos.

Relativo aos ganhos mensais percebidos pelas empregadas domésticas, o tratamento dos dados revela uma queda salarial. Este montante é representado por uma fração de 0,89 de um salário mínimo conforme a tabela 2. A perda salarial percebida pelas empregadas domésticas habitantes da área de estudo pode estar relacionada aos benefícios nos processos de formalização deste tipo de atividade socioprofissional. Benefícios previdenciários, vale-transporte, cesta básica, e outras despesas atribuídas ao empregador no processo de formalização, podem ter contribuído para o decréscimo salarial.

O decréscimo salarial foi também acompanhado pela queda relativa do emprego informal e o consequente acréscimo da formalização das trabalhadoras domésticas. A tabela 3 resume os principais aspectos sobre a informalidade do trabalho das empregadas domésticas entre 2000 e 2010, ocorridos na área de estudo. Em valores proporcionais, o conjunto das empregadas domésticas formais registrou um acréscimo de $0,39 \%$ no Oeste e no Sudoeste da RMSP, tomando-se como base a época inicial do período. Os municípios de Taboão da Serra, com taxa de $-2,11 \%$, Vargem Grande Paulista, com -1,07\%, e Embu das Artes, com $0,68 \%$ foram as unidades administrativas que registraram taxas negativas relativas à formalidade do emprego doméstico feminino. Quanto à informalidade empregatícia, houve um decréscimo de $-4,47 \%$ em média. Apesar de Vargem Grande Paulista e Taboão da Serra apresentarem acréscimos negativos relativos ao emprego doméstico formal, são também as unidades administrativas em que foram verificados os maiores decréscimos quanto à informalidade. 


\begin{tabular}{|c|c|c|c|c|c|c|}
\hline \multicolumn{7}{|c|}{ Tabela 3 - Balanço das trabalhadoras em serviços domésticos formais e informais entre 2000 e 2010.} \\
\hline \multirow[t]{3}{*}{ Município } & $\begin{array}{l}\text { Proporção de } \\
\text { domésticas } \\
\text { formais }\end{array}$ & $\begin{array}{l}\text { Proporção de } \\
\text { domésticas } \\
\text { formais }\end{array}$ & $\begin{array}{c}\text { Diferença } \\
\text { Proporcional das } \\
\text { domésticas formais }\end{array}$ & $\begin{array}{l}\text { Proporção de } \\
\text { domésticas } \\
\text { informais }\end{array}$ & $\begin{array}{l}\text { Proporção de } \\
\text { domésticas } \\
\text { informais }\end{array}$ & $\begin{array}{c}\text { Diferença } \\
\text { Proporcional das } \\
\text { domésticas informais }\end{array}$ \\
\hline & 2010 & 2000 & 2010-2000 & 2010 & 2000 & $2010-2000$ \\
\hline & $(\%)$ & $(\%)$ & $(\%)$ & $(\%)$ & $(\%)$ & $(\%)$ \\
\hline Barueri & 8,47 & 7,50 & 0,97 & 7,47 & 12,11 & $-4,64$ \\
\hline Carapicuíba & 8,70 & 7,08 & 1,62 & 8,08 & 11,13 & $-3,05$ \\
\hline Cotia & 8,96 & 8,47 & 0,49 & 9,36 & 14,48 & $-5,13$ \\
\hline Embu & 11,19 & 11,86 & $-0,68$ & 12,81 & 15,68 & $-2,86$ \\
\hline Itapecerica da Serra & 11,73 & 9,17 & 2,56 & 13,71 & 17,85 & $-4,14$ \\
\hline Itapevi & 10,13 & 8,60 & 1,53 & 10,72 & 15,69 & $-4,97$ \\
\hline Jandira & 8,99 & 8,44 & 0,55 & 9,60 & 15,03 & $-5,42$ \\
\hline Osasco & 5,37 & 5,36 & 0,01 & 7,73 & 10,07 & $-2,34$ \\
\hline Taboao da Serra & 5,82 & 7,94 & $-2,11$ & 6,56 & 12,07 & $-5,51$ \\
\hline \multirow[t]{2}{*}{ Vargem Grande Paulista } & 7,15 & 8,23 & $-1,07$ & 9,61 & 16,23 & $-6,62$ \\
\hline & $\begin{array}{l}\text { Renda média } \\
\text { das domésticas } \\
\text { formais } \\
2010 \\
\text { (s.m.) }\end{array}$ & $\begin{array}{l}\text { Renda média } \\
\text { das domésticas } \\
\text { formais } \\
2000 \\
\text { (s.m.) }\end{array}$ & $\begin{array}{l}\text { Diferença da renda } \\
\text { das domésticas } \\
\text { formais } \\
2010-2000 \\
\text { (s.m.) }\end{array}$ & $\begin{array}{c}\text { Renda média } \\
\text { das domésticas } \\
\text { informais } \\
\mathbf{2 0 1 0} \\
\text { (s.m.) }\end{array}$ & $\begin{array}{c}\text { Renda média } \\
\text { das domésticas } \\
\text { informais } \\
2000 \\
\text { (s.m.) }\end{array}$ & $\begin{array}{l}\text { Diferença da renda } \\
\text { das domésticas } \\
\text { informais } \\
2010-2000 \\
\text { (s.m.) }\end{array}$ \\
\hline Barueri & 1,51 & 2,41 & $-0,90$ & 0,92 & 1,75 & $-0,83$ \\
\hline Carapicuíba & 1,38 & 2,43 & $-1,05$ & 1,04 & 1,92 & $-0,88$ \\
\hline Cotia & 1,44 & 2,37 & $-0,93$ & 1,06 & 1,69 & $-0,63$ \\
\hline Embu & 1,46 & 2,60 & $-1,14$ & 1,06 & 2,17 & $-1,11$ \\
\hline Itapecerica da Serra & 1,39 & 2,33 & $-0,94$ & 0,94 & 1,83 & $-0,89$ \\
\hline Itapevi & 1,40 & 2,46 & $-1,06$ & 0,96 & 1,67 & $-0,71$ \\
\hline Jandira & 1,49 & 2,36 & $-0,87$ & 0,81 & 1,81 & $-1,00$ \\
\hline Osasco & 1,35 & 2,25 & $-0,90$ & 0,93 & 1,82 & $-0,89$ \\
\hline Taboao da Serra & 1,68 & 2,46 & $-0,78$ & 1,23 & 2,02 & $-0,79$ \\
\hline Vargem Grande Paulista & 1,19 & 2,09 & $-0,90$ & 0,90 & 1,48 & $-0,58$ \\
\hline
\end{tabular}

Os rendimentos mensais percebidos pelas empregadas domésticas registraram quedas tanto para as pessoas com vínculo formal quanto para aquelas sem este vínculo. As trabalhadoras em serviços domésticos com vínculo formal tiveram uma redução em seus ganhos mensais equivalente a 0,95 do salário mínimo, e as trabalhadoras informais a 0,83 do salário mínimo. Apesar das baixas nos ganhos, é necessário ressaltar que, tanto em 2000 quanto em 2010, os ganhos das domésticas com vínculos formais e aquelas com vínculos informais foram maiores em 0,56 salários mínimos em 2000, e de 0,44 salários mínimos em 2010, em favor das primeiras, ou seja, as domésticas com vínculos formais percebem maiores rendimentos. Nesses primeiros dez anos do século XXI, os resultados do tratamento dos dados demonstram melhora no nível de instrução das mulheres prestadoras de serviços domésticos (Tabela 4). No período, houve diminuição proporcional das empregadas domésticas com ensino fundamental, enquanto, simultaneamente, ocorreu um aumento na proporção daquelas com o ensino médio. Essas variações foram da ordem de $-9,21 \%$ em 
média, em relação ao ensino fundamental, portanto uma queda, e o aumento de $12,87 \%$ em média, relativo ao ensino médio. As taxas não podem ser desconsideradas, pois comprovam a melhora do nível de instrução das empregadas domésticas. A melhora no nível educacional das mulheres pode ser uma das causas do decréscimo proporcional das trabalhadoras em serviços domésticos em relação à PEA feminina. Esse aumento no nível de instrução significa qualificação e, portanto, maiores possibilidades de alçar níveis ocupacionais superiores no mercado de trabalho. Por outro lado, melhor nível de instrução contribui para a formalização no emprego.

\begin{tabular}{|c|c|c|c|c|c|c|}
\hline \multirow[b]{2}{*}{ Município } & \multicolumn{5}{|c|}{ Tabela 4 -Nível de instrução das trabal hadoras em serviços domésticos entre 2000 e 2010} & \multirow[b]{2}{*}{$\begin{array}{c}\text { Diferença Proporciona } \\
\text { das domésticas com } \\
\text { ensino médio } \\
2010-2000 \\
(\%)\end{array}$} \\
\hline & $\begin{array}{c}\text { Proporção de } \\
\text { domésticas com ensino } \\
\text { fundamental } \\
2010 \\
(\%)\end{array}$ & $\begin{array}{c}\text { Proporção de } \\
\text { domésticas com ensino } \\
\text { fundamental } \\
2000 \\
(\%)\end{array}$ & $\begin{array}{c}\text { Diferença Proporcional } \\
\text { das domésticas com } \\
\text { ensino fundamental } \\
2010-2000 \\
(\%)\end{array}$ & $\begin{array}{c}\text { Proporção de } \\
\text { domésticas com ensino } \\
\text { médio } \\
2010 \\
(\%)\end{array}$ & $\begin{array}{c}\text { Proporção de } \\
\text { domésticas com ensino } \\
\text { médio } \\
2000 \\
(\%)\end{array}$ & \\
\hline Barueri & 56,90 & 74,70 & $-17,81$ & 26,17 & 9,78 & 16,39 \\
\hline Carapicuíba & 64,44 & 76,52 & $-12,08$ & 19,59 & 9,32 & 10,27 \\
\hline Cotia & 66,14 & 74,17 & $-8,03$ & 22,09 & 7,57 & 14,52 \\
\hline Embu & 72,07 & 74,18 & $-2,11$ & 21,50 & 9,27 & 12,23 \\
\hline Itapecerica da Serra & 66,03 & 68,66 & $-2,63$ & 19,92 & 8,98 & 10,94 \\
\hline Itapevi & 67,45 & 76,81 & $-9,36$ & 20,52 & 6,63 & 13,89 \\
\hline Jandira & 61,74 & 71,61 & $-9,87$ & 24,18 & 6,94 & 17,24 \\
\hline Osasco & 61,97 & 75,62 & $-13,65$ & 18,80 & 8,55 & 10,25 \\
\hline Taboao da Serra & 59,93 & 73,80 & $-13,87$ & 26,82 & 10,18 & 16,64 \\
\hline Vargem Grande Paulista & 69,93 & 72,57 & $-2,64$ & 16,08 & 9,73 & 6,35 \\
\hline
\end{tabular}

A participação das mulheres brancas, negras e pardas neste segmento do mercado de trabalho demonstra variações significativas (Tabela 5). No período em análise sucedeu uma queda de empregadas domésticas brancas, cuja mudança foi da ordem de $-4,93 \%$, em média. Apenas Vargem Grande Paulista, com a diferença proporcional de 1,21\% entre as datas, apresentou uma variação positiva em favor das mulheres brancas, enquanto nos demais municípios o número de empregadas domésticas brancas decresceu, sendo registrado o acréscimo negativo mais contundente imputado a Barueri (-12,51\%), e ocupando o segundo posto Itapevi $(-8,70)$. Por outro lado, as empregadas domésticas negras contribuíram no computo geral com pequeno acréscimo, da ordem de 2,37\%, existindo neste balanço duas unidades administrativas que apresentaram decréscimos insignificantes, Vargem Grande Paulista e Osasco, com valores de $-1,11 \%$ e $-0,84 \%$ respectivamente. 0 acréscimo relevante pertence ao município de Carapicuíba, com alteração proporcional de 4,55\%. Em relação às empregadas domésticas pardas, registra-se um acréscimo equivalente à queda observada para as empregadas brancas, proporção aproximada de $4,14 \%$. Coube a Osasco o registro do maior acréscimo, de 7,02\%, cujo valor não deve ser desconsiderado. 


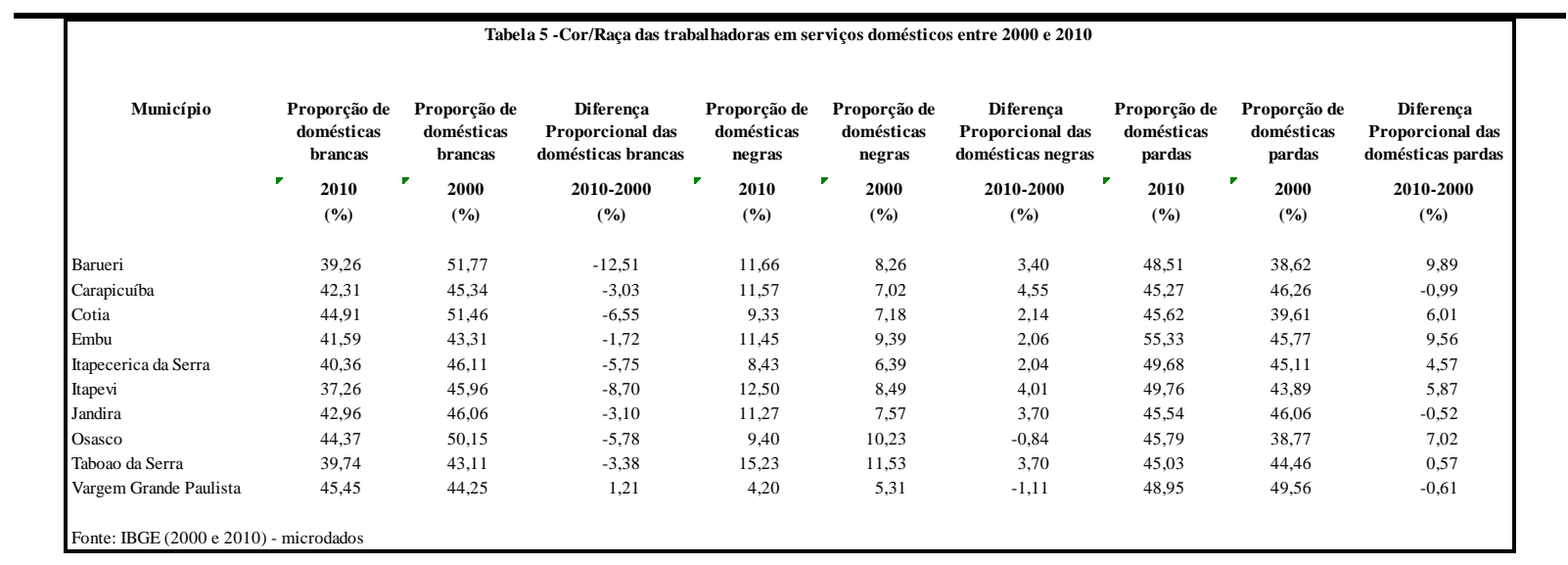

A origem do fluxo migratório das empregadas domésticas inverteu-se totalmente no decênio (tabela 6). Enquanto o ano de 2000 registrou um fluxo migratório proveniente da região nordeste, no ano de 2010 a origem das migrantes passou a ser a própria Região Sudeste. As empregadas nordestinas detinham uma proporção média de $13,36 \%$ no movimento migratório em 2000, passaram a registrar, praticamente, a metade deste valor em 2010, consequentemente resultando em um balanço negativo de $-5,75 \%$. Coube a Osasco, mais uma vez, o registro do menor valor proporcional de $-9,20 \%$. Se por um lado, houve a diminuição no fluxo de empregadas domésticas nordestinas, por outro, registrou-se um aumento das migrantes procedentes dos estados do sudeste. No ano de 2000 , apenas $2,82 \%$ das migrantes tinham origem nas unidades da federação do sudeste, já em 2010, 14,31\% das migrantes eram oriundas desta região. O sudeste no cômputo final contribuiu com $11,49 \%$ das empregadas domésticas migrantes, sendo que Taboão da Serra foi a unidade administrativa com maior representatividade, revelada pela proporção de $16,79 \%$. Não menos importantes, com proporções próximas a essas últimas, estão os territórios de Vargem Grande Paulista $(15,90 \%)$ e de Itapevi $(15,30 \%)$. Afirmar que os nordestinos não contribuem mais com o crescimento populacional dos municípios da Região Metropolitana de São Paulo seria uma conclusão precoce, pois uma análise aprofundada dos dados poderá revelar traços dos movimentos migratórios intra-metropolitanos e intra-estaduais efetuados pela população. 


\begin{tabular}{|c|c|c|c|c|c|c|}
\hline \multirow[b]{2}{*}{ Município } & Tabela 6 -Orige & das trabalhado & ras em serviços doméstic & os migrantes entr & e 2000 e 2010 & \\
\hline & $\begin{array}{l}\text { Proporção de } \\
\text { domésticas } \\
\text { nordestinas } \\
2010 \\
(\%)\end{array}$ & $\begin{array}{l}\text { Proporção de } \\
\text { domésticas } \\
\text { nordestinas } \\
2000 \\
(\%)\end{array}$ & $\begin{array}{c}\text { Diferença Proporcional } \\
\text { das domésticas } \\
\text { nordestinas } \\
2010-2000 \\
(\%)\end{array}$ & $\begin{array}{l}\text { Proporção de } \\
\text { domésticas do } \\
\text { Sudeste } \\
2010 \\
(\%)\end{array}$ & $\begin{array}{l}\text { Proporção de } \\
\text { domésticas do } \\
\text { Sudeste } \\
2000 \\
(\%)\end{array}$ & $\begin{array}{c}\text { Diferença Proporcional } \\
\text { das domésticas do } \\
\text { Sudeste } \\
2010-2000 \\
(\%)\end{array}$ \\
\hline Barueri & 7,82 & 15,01 & $-7,18$ & 14,08 & 5,23 & 8,85 \\
\hline Carapicuíba & 8,02 & 14,27 & $-6,25$ & 10,98 & 2,65 & 8,33 \\
\hline Cotia & 9,04 & 11,46 & $-2,42$ & 15,93 & 3,69 & 12,24 \\
\hline Embu & 7,58 & 12,91 & $-5,33$ & 14,54 & 3,05 & 11,49 \\
\hline Itapecerica & 5,87 & 15,37 & $-9,49$ & 13,15 & 2,00 & 11,16 \\
\hline Itapevi & 7,31 & 10,77 & $-3,45$ & 16,75 & 1,45 & 15,30 \\
\hline Jandira & 8,92 & 14,83 & $-5,91$ & 12,91 & 3,47 & 9,44 \\
\hline Osasco & 6,99 & 16,20 & $-9,20$ & 7,43 & 2,05 & 5,38 \\
\hline Taboao & 8,28 & 14,82 & $-6,54$ & 20,53 & 3,74 & 16,79 \\
\hline Vargem & 6,29 & 7,96 & $-1,67$ & 16,78 & 0,88 & 15,90 \\
\hline
\end{tabular}

\section{CONSIDERAÇÕES FINAIS}

As Sub-Regiões Oeste e Sudoeste da Região Metropolitana de São Paulo possuem componentes típicos caracterizadores das atuais zonas pericentrais, ou fronteiras urbanas, por apresentar elementos complexos e por exibir disparidades internas. Esta área da RMSP caracteriza-se por abrigar várias categorias socioprofissionais, entre elas aquelas em que os indivíduos desempenham trabalhos destituídos de conteúdo.

Quanto as mulheres inseridas no mercado de trabalho, pode-se constatar um aumento significativo em sua participação. A pesquisa revela melhor nível de instrução da população economicamente ativa feminina, portanto alçam novos postos no mercado de trabalho, deixando o circuito inferior da economia urbana.

Em relação às domésticas, a análise dos dados possibilita antever melhores níveis educacionais e maior formalização das mulheres incluídas nesta atividade. Consequentemente, houve uma queda em rendimentos, o que pode ser atribuído às novas atribuições dos empregadores.

Enfim, os dados fornecidos pelos órgãos oficiais, possibilitam realizar diagnósticos caracterizadores da sociedade, principalmente aqueles relacionados ao mercado de trabalho. 


\section{BIBLIOGRAFIA}

AMORIM FILHO, O. B. Um modelo de Zoneamento Morfológico-Funcional do espaço intraurbano das cidades médias de Minas Gerais In: Amorim Filho, O. B.; SenA Filho, N. de. $\boldsymbol{A}$ morfologia das cidades médias. Goiânia, Ed. Vieira, 2005. pp.17 - 69 cap.1. (ISBN 85-8977920-3)

BERNARDES, ADRIANA. A nova divisão territorial do trabalho brasileira e a produção de informações na cidade de São Paulo (as empresas de consultoria). In: SANTOS, MILTON; SILVEIRA, MARIA LAURA. O Brasil: território e sociedade no início do século XXI. Rio de Janeiro, Record, 2011. PP. 413 - 432. 15a Ed.

BORGES, ÂNGELA. Reestruturação produtiva e trabalho na Região Metropolitana de Salvador: a construção de um novo patamar de precariedade. Cadernos Metrópole, _(14): $85-101,2005$.

CASTELLS, MANUEL. A Sociedade em rede. São Paulo, Paz e Terra, 1999. V.1. 698 p. Trad. Roneide Venancio Majer.

COSTA, LYGIA; RIBEIRO, MARCELO. Estrutura ocupacional e mercado de trabalho feminino. e-metropolis, 1 (2): $25-35,2010$.

FRÚGOLI JÚNIOR, HEITOR. Centralidade em São Paulo: Trajetórias, conflitos e negociações na Metrópole. São Paulo, EDUSP, 2006. 264 p.

FUNDAÇÃO INSTITUTO BRASILEIRO DE GEOGRAFIA E ETATÍSTICA. Censo demográfico 2000 documentação dos microdados da amostra. Rio de Janeiro, FIBGE, 2002. 166 p.

FUNDAÇÃO INSTITUTO BRASILEIRO DE GEOGRAFIA E ETATÍSTICA. Censo demográfico 2000 agregado por setores censitários. Rio de Janeiro, FIBGE, 2003. 157 p. 2a Ed.

GUIA, GEORGE ALEX DA; CIDADE, LÚCIA CONY FARIA. Segregação residencial e reprodução das desigualdades socioespaciais no aglomerado urbano de Brasília. Cadernos Metrópole, 12 (22); $145-168$, jan/jun 2010.

LEITE, MÁRCIA DE PAULA. Trabalho e sociedade em transformação: mudanças produtivas e atores sociais. São Paulo, Editora Fundação Perseu Abramo, 2003. 223 p. 
MAMMARELLA, ROSETTA; BARCELLOS, TANYA M.; KOCH, MIRIAN REGINA. Mudanças socioespaciais e estrutura social da Região Metropolitana de Porto Alegre: anos 1980 e 1990. Cadernos Metrópole,_(6): 79 - 103, 2001.

MEYER, REGINA MARIA PROSPERI; GROSTEIN, MARTA DORA; BIDERMAN, CIRO. São Paulo: Metrópole. São Paulo, EDUSP/Imprensa oficial, 2004. 293 p.

SANTOS, MILTON 0 espaço dividido: Os dois circuitos da economia urbana dos países subdesenvolvidos. São Paulo, EDUSP, 2004. 433 p. 2ª Ed.

SANTOS, Milton. A natureza do espaço: técnica e tempo, razão e emoção. São Paulo, EDUSP, 2006. 384p. 4a Ed.

SANTOS, MILTON. Manual de Geografia urbana. São Paulo, EDUSP, 2008. 228 p. 3a Ed.

SANTOS, MILTON. Pobreza urbana. São Paulo, EDUSP, 2009. 136 p. 3 a Ed.

SANTOS, MILTON; SILVEIRA, MARIA LAURA. O Brasil: território e sociedade no início do século XXI. Rio de Janeiro, Record, 2011. 477 p. 15a Ed.

SILVEIRA, MARIA LAURA. São Paulo: os dinamismos da pobreza. In: CARLOS, ANA FANI ALESSANDRI; OLIVEIRA, ARIOVALDO UMBELINO DE (Orgs.). Geografias de São Paulo: Representações e crise da Metrópole. São Paulo, Contexto, 2004. pp. 59 - 71. v.1.

TORRES, Haroldo A fronteira paulistana. In: MARQUES, Eduardo; TORRES, Haroldo. São Paulo: segregação, pobreza e desigualdades. São Paulo, SENAC, 2005. p. 101 - 119. Cap. 4. (ISBN 85-7359-428-4). 